\title{
HISTÓRIA NO VIDEOGAME, VIDEOGAME COMO HISTÓRIA
}

\author{
History in videogames, videogames as history
}

\section{Marco de Almeida Fornaciari*}

Resenha de: CHAPMAN, Adam. 2016. Digital games as history: how videogames represent the past and offer access to historical practice. Nova York, Routledge, 290 p.

Jogos eletrônicos, jogos digitais, videogames; seja como for que os chamemos, eles têm consistentemente atraído maior atenção da comunidade acadêmica desde, no mínimo, a última década do século XX. À medida em que esses jogos se tornam uma parte cada vez maior do mercado global de artefatos culturais - e do cotidiano de mais e mais pessoas -, a importância de compreender suas especificidades midiáticas, sua relevância socioeconômica, seu impacto psicológico e seus modos de divulgação de discursos sobre os mais variados temas passa a ser progressivamente mais difícil de ignorar.

Em meio a essa diversidade de temas, a História ${ }^{1}$ não foi esquecida. Autores como Chris Kempshall, Jeremiah McCall, Matthew Kappell, Kurt Squiree outros dedicaram-se ao estudo de jogos que, de alguma forma, apresentam relação com narrativas históricas, geralmente concentrando-se em seu conteúdo ou sua potencial utilidade em contextos educacionais. Movimento semelhante ocorre no Brasil, como exemplificado pelo trabalho pioneiro de Christiano Santos e autores como Alex Alvarez Silva, Helyom Telles, Hezrom Vieira, Lynn Alves, Mariano de Azevedo Júnior, Robson Bello e este que vos escreve. Nesse sentido, William Uricchio se destaca como caso um tanto dissonante: seu "Simulation, history and computer games", publicado em 2005, concentra-se não no conteúdo dos "jogos históricos” ou suas possíveis aplicações em outras áreas, mas na interpretação deles como uma forma histórica em si.

É essa proposta que orienta Adam Chapman em "Digital games as history: how videogames represent the past and offer access to historical practice", publicado onze anos depois, em 2016. Ao longo de suas 290 páginas, o pesquisador do Departamento de Educação, Comunicação e Aprendizagem da Universidade de Gotemburgo deseja, mais do que pensar a relação entre videogames e História, sugerir que games históricos são histórias. No processo, produz uma obra indispensável a qualquer interessado em ambas as perspectivas, que nos oferece os primeiros passos mais firmes em direção a algo cuja construção ainda engatinha: um arcabouço teórico-metodológico específico para a análise e compreensão histórica de videogames.

O autor afirma que seu livro tem três objetivos centrais: oferecer um arcabouço (framework) para a análise de jogos digitais históricos; descrever a natureza da representação histórica em jogos digitais; e descrever o uso potencial de jogos digitais como sistemas para "historiar" (bistorying), ou seja, como obras que oferecem acesso a práticas históricas. Esses objetivos emergem de três questões: como podemos abordar tais jogos históricos enquanto estudiosos interessados neles? Como

\footnotetext{
* Doutorando em História Social da Cultura pela Pontifícia Universidade Católica do Rio de Janeiro, Brasil. Email: mfornaciari@gmail.com

1 No sentido koselleckiano de singular coletivo, que inclui toda a humanidade em um único processo temporal, refiro-me à "História". Ao tratar de narrativas sobre sociedades humanas e suas transformações através do tempo, falo em "história(s)".
} 
eles representam o passado? Que oportunidades oferecem a jogadores no tocante a interagir ativamente com a História e práticas históricas? Pode-se perceber, portanto, que o foco é a compreensão do objeto a partir de três perspectivas: a do estudioso que deseja analisar jogos; a do desenvolvedor que os cria e, no processo, embute neles representações históricas baseadas em sua própria interpretação da História e de eventos históricos; e a do jogador que, através deles, teria acesso a práticas históricas.

Talvez a principal contribuição de "Digital games as history" seja a referente à primeira perspectiva. Através do exame do que considera cinco estruturas formais centrais - simulação e epistemologia; tempo; espaço; narrativa; "possibilidades" (affordances) -, Chapman nos fornece um amplo conjunto de conceitos úteis para uma análise formalista da relação videogame-História. Ele reconhece e se baseia nas obras tanto de historiadores quanto de teóricos dos game studies que podem oferecer algo de interessante para esse fim, mas não se limita a fazer uma mera transposição de conceitos; constrói seu arcabouço conceitual pensando especificamente em jogos históricos e na necessidade de compreendê-los em suas especificidades. Nesse ponto, o recurso estilístico de utilizar letras itálicas para destacar os conceitos centrais facilita a leitura, principalmente para aqueles leitores que não dominam todos os campos de estudo pelos quais Chapman transita, que vão da historiografia à psicologia ecológica.

A discussão sobre os modelos de simulação encontrados em jogos é um bom exemplo do modus operandi do autor ao longo do livro. Ele parte de uma perspectiva teórica geral - neste caso, a de que, uma vez que obras ditas "populares" que abordam o passado são tão históricas quanto aquelas feitas por autores acadêmicos, pressupõem uma abordagem epistemológica desse passado. Com base nisso, constrói uma série de conceitos que servem como ferramentas metodológicas para a compreensão de videogames a partir dessa perspectiva. Na análise conjunta de simulação e epistemologia, associa o que chama de modelo de simulação realista, caracterizado por uma tentativa de mostrar o passado como ele foi experimentado por agentes históricos, ao paradigma reconstrucionista, e o modelo conceitual, caracterizado por sua tentativa de falar sobre o passado através da construção de regras de funcionamento, ao paradigma construcionista. Nesse processo, atende tanto ao objetivo de oferecer um arcabouço para a análise de jogos digitais históricos quanto ao de descrever a natureza da representação histórica em jogos digitais.

Se quaisquer interessados em jogos históricos podem encontrar utilidade nessas propostas metodológicas de Chapman, são suas bases teóricas que provavelmente causarão controvérsias. Ora, nosso autor faz questão de sublinhar que as interpretações acerca do legado do pós-modernismo não são consensuais (p. 7), mas planta os dois pés com bastante firmeza nessa tradição. Isso fica claro quando notamos que, dentre os principais autores que compõem sua fundamentação teórica, três dos mais citados são Robert Rosenstone (57 menções), Alun Munslow (43 menções) e Hayden White (18 menções), classificados pelo próprio Chapman como "teóricos pós-modernistas”. Na historiografia, críticas à perspectiva pós-moderna frequentemente se concentram na dimensão epistemológica, uma vez que tal perspectiva tende a questionar a autoridade que se arrogam as histórias acadêmicas e abrir espaço para a legitimação de outros tipos de obras históricas. Detenhamo-nos na relevância desse debate para "Digital games as history".

Chapman faz duplo uso da interpretação pós-moderna: em primeiro lugar, ela é fundamental para ressaltar a importância dos videogames enquanto obras históricas. Aproximando-se do ponto de vista do que se convencionou chamar "história pública", ele ressalta que, ao contrário do que afirmam alguns historiadores, o público se interessa pela História - apenas não por aquela produção histórica feita segundo os moldes acadêmicos tradicionais. O público assiste a filmes 
sobre o passado, lê romances históricos, visita museus, coleciona objetos históricos e, como nos interessa aqui, joga videogames históricos. Portanto, tais obras informam a maneira como esse público concebe o passado e, por isso, é justificável que um historiador se interesse em compreendê-las. Dessa forma, Chapman realiza para os videogames o mesmo movimento que historiadores do cinema realizaram para justificar seu objeto de pesquisa ao longo do século XX. Até aí, nenhuma novidade; boa parte dos autores que lidam com a relação entre jogos e História fazem o mesmo para justificar suas pesquisas.

Mas Chapman não para por aí: ele ressalta que, quando alguém diz que o público não se interessa pela História, geralmente deixa implícito querer dizer que ele não se interessa pela História "certa", ou seja, as narrativas consideradas verdadeiras, produzidas no suporte midiático adequado - o texto escrito. Afinado com o trabalho de autores como Rosenstone, Chapman descarta a ideia de que as únicas histórias legítimas são aquelas feitas por escrito; para ele, a produção histórica em outras mídias não é muito diferente em termos de construção narrativa e, portanto, em legitimidade. Cita Munslow para sugerir que cineastas (e autores de romances históricos, criadores de dramas históricos para TV e desenvolvedores de jogos históricos), por exemplo, usam argumentos preferidos, avaliam o passado ideologicamente, fazem uso da retórica, contraem ou estendem o tempo etc. - todas operações que acadêmicos escrevendo histórias também fazem. Ao mesmo tempo, reconhece que a forma não pode ser radicalmente separada do conteúdo, o que está no cerne de sua tentativa de analisar as possibilidades que a forma "videogame" oferece no tocante a maneiras de representar e escrever histórias.

As controvérsias repousam principalmente sobre esse segundo uso, a aproximação feita entre a historiografia acadêmica e essas ditas "histórias populares". Chapman ressalta com clareza as semelhanças entre esses dois polos, seja ao destacar as operações que autores trabalhando nos dois campos realizam, seja ao enfatizar que nenhum deles é capaz de "retratar verdades" pura e simplesmente. Para ele, "a história sempre é constituída sob premissas ou decisões morais e ideológicas” (Chapman, 2016, p. 8), o que não é um afirmativa particularmente problemática em si; torna-se polêmica, contudo, quando não há grande interesse em ressaltar as diferenças entre a historiografia acadêmica - orientada por preceitos metodológicos rigorosos que buscam, no mínimo, verossimilhança - e obras que lidam com a História sem a mesma preocupação. É claro que, para fins de justificar seu objeto de estudo, aproximar a história popular da acadêmica é mais importante; no entanto, se é verdade que nosso autor considera que "isso não significa que não há diferenças entre histórias e formas populares e profissionais" (Chapman, 2016, p. 9), ele não parece muito preocupado em esclarecer quais seriam. Em tempos de fake news e descrença na competência de profissionais treinados para analisar a História, é uma posição no mínimo temerária. Sem critérios para hierarquizar epistemologicamente as narrativas históricas, com que base Chapman pode afirmar, por exemplo, ser "problemático" o fato de que "na maioria dos jogos históricos [...] heróis são majoritariamente brancos, ocidentais e do sexo masculino" (Chapman, 2016, p. 147)?

Isso nos leva a outra questão, associada ao terceiro objetivo do livro: partindo dessa postura de legitimação de quaisquer narrativas históricas, Chapman considera que, ao jogar um jogo histórico, o jogador está fazendo história, isto é, produzindo uma narrativa histórica em conjunto com o desenvolvedor. Por esse motivo, utiliza os termos desenvolvedor-historiador jogador-historiador ao longo do livro. Por relevante que seja tentar compreender como jogadores podem, de fato, fazer uso de jogos para produzir narrativas sobre o passado, é um salto um tanto exagerado supor que o ato de jogar um jogo histórico é, em si, produtor de uma narrativa histórica. A narrativa produzida ao jogar não necessariamente dirá respeito ao passado, mas a um espaço de possibilidades definido 
pelos desenvolvedores que está, este sim, baseado em suas interpretações acerca do passado. Um jogador pode, por exemplo, jogar Europa Universalis IV com o objetivo de recriar a narrativa que conhece acerca da unificação alemã; um professor pode tentar representar, através do jogo, o mesmo processo para seus alunos; mas um jogador que, digamos, opte por assumir o controle da Suécia em uma partida e colonize a América do Sul não está, parece-me, produzindo uma narrativa histórica, mas operando dentro das regras definidas pelos desenvolvedores - que buscam representar como a História "funciona" de acordo com a visão destes - e criando fatos novos. No máximo, emerge daí uma narrativa contrafactual, que explora o que poderia ter acontecido com base no que se entende serem "leis" (conceito em si questionável) teóricas do processo histórico.

Creio que a obra com a qual Chapman nos presenteia, por sua aparente capacidade de atrair adeptos e detratores, pode vir a se tornar um texto clássico para os estudiosos de jogos históricos. Sua capacidade de definir com clareza conceitos úteis na compreensão e análise da relação desses jogos com a História - ou mesmo no entendimento deles como histórias - há de ser reconhecida mesmo pelos mais ardentes críticos do pós-modernismo. Já seus fundamentos teóricos provavelmente se demonstrarão menos palatáveis. Seja como for, é impensável não recomendar sua leitura.

Resenha recebida em: 27/03/2019

Resenha aceita em: 30/05/2019 